\title{
HUBUNGAN PEMESAN DAN PELARAS DALAM PENENTUAN LARASAN GAMALAN BANJAR
}

\author{
Novyandi Saputra \\ Pengkajian Seni Musik \\ Pascasarjana ISI Surakarta \\ novyandisaputra05@gmail.com
}

\begin{abstract}
ABSTRAK
Proses pelarasan gamalan Banjar sangat berkaitan antara pemesan dan pelaras gamalan Banjar. Pemesan yang menginginkan gamalan Banjar memiliki kreteria sendiri terhadap gamalan yang akan dibuatnya melalui pelaras gamalan Banjar. Komponen yang mempengaruhi pemesan dalam membuat gamalan Banjar adalah modal budaya, selera, kedekatan timbre suara, dan kekuatan kapital yang dimilikinya.sedangkan pelaras gamalan Banjar memiliki pengetahuan atas pembentukan tumbang antar bilahan nada yang berdasarkan pada karateristik rasa musikal budayanya. Peneliti menggunakan metode penelitian kualitatif sebagai metode utama dalam upaya mengumpulkan informasi dan data lapangan yang di dapatkan pada saat pengumpulan data. Metode kuantitatif juga digunakan sebagai metode bantu untuk menghitung dan memvalidasi data frekuensiyang didapatkan dari instrumen gamalanBanjar yang ada di lapangan, sehingga peneliti bisa mendapatkan gambaran jelas. Kerangka konseptual yang berdasarkan pada pengetahuan emperis pemesan dan pelaras GamalanBanjar menjadi dasar analisis untuk mengungkap hubungan antara pemesan dan pelaras gamalan Banjar. Perbedaan ini tergambar jelas pada frekuensi bilahan nada-nada gamalan Banjar, sedangkan jangkah dan gembyangannya tidak mengalami perubahan yang signifikan. Perbedaan frekuensi bilahan nada tersebut dilandasi oleh timbre suara dalang yang berbeda-beda. gamalan Banjar yang telah selesai dilaras akan menjadi representatif pemiliknya. Caruk dan payau menjadi penanda kualitas hasil dari hubungan antara pemesan dan pelaras gamalan Banjar.
\end{abstract}

Kata kunci : Pelarasan, Gamalan Banjar, hubungan, Pemesan, Pelaras

\begin{abstract}
Within the process of gamalan Banjar tuning, the relationship between the buyers and the tuner of gamalan Banjar is taken into account. The buyers who order gamalan Banjar must have their own criteria toward the gamalan which is going to be produced by the tuner of gamalan Banjar. The components that are taken into consideration by the buyers when ordering gamalan Banjar is the cultural principle, taste, the proximity of voice timbre, and the finance capability they possess. Furthermore, the tuner of gamalan Banjar has a cognition in contriving the strides within the frequency of tone keys which based on the characteristics of its cultural music taste. The researcher utilizes qualitative method as the primay method in collecting information and data on the field in the stage of data collection. The quantitative method as a secondary method here is used to assist the researcher to calculate and validate the frequency of the data collected from gamalan Banjar instrument which is present on the field so he could get a clearer picture. A conceptual framework which is based on the empirical knowledge about the buyers and the tuner of gamalan Banjar becomes the basis of the analysis to uncover the relationship between the buyer and tuner of gamalan Banjar. This distinction is clearly illustrated in the frequency of tones keys of gamalan Banjar, whereas the stride and its gembyangan do not change significantly. The differences in the frequency of the tone pitches rely on the varied voice timbre of the mastermind. gamalan Banjar who have completed tuned will be the representative owners. Caruk and payau become a mark of quality results from the relationship between the buyer and the tuner of gamalan Banjar
\end{abstract}

Keywords : tuning, Gamalan Banjar, relationship, buyers, tuner. 


\section{A. PENDAHULUAN}

Dalam proses pelarasan gamalan Banjartidak bisa dipisahkan tentang hubungan pemesan dan pelarasgamalandalam penentuan larasan yang akan digunakan. Pemesan yang memesan gamalan Banjar, memiliki kuasa sendiri terhadap gamalan yang akan dibuatnya. Perbedaan yang ada antara gamalan yang satu dengan yang lainnya terbentuk dari konstruksi komponen-komponen yang melingkupi pemesan.

Seorang pemesan yang bisa seorang dalang atau bukan dalang. Perbedaan antara pemesan yang seorang dalang dan pemesan yang bukan dalang terletak dari cara penentuan larasannya. Peranan suara dalang yang menjadi dasar pelarasan mampu menjadi daya tarik para pemesan. Bagaimana pemesan membuat gamalan yang dibantu para pelaras gamalan agar sesuai dengan suara dalang yang diinginkannya, hingga suara dalang tersebut dijadikan acuan pelarasan gamalan Banjar yang diinginkannya. Timbre suara yang dekat antara pemesan dan dalang menjadi salah satu bagian yang tanpa sadar membentuk keinginan seorang pemesan dalam hal penentuan larasan dalang siapa yang akan digunakan dalam pelarasan gamalan yang akan dibuat.

Hubungan yang terjadi antara pemesan dan pelaras dalam pembentukan larasan ini terjadi ada saat proses marasukgamalan Banjar. kuasa pemesan dalam membentuk larasan akan direpresentasikan oleh pelaras lewat laku kerja dan penentuan jangkah-jangkah serta $u k u r a n^{1}$ antar bilah nada, sehingga terbentuk larasan yang sesuai dengan selera pemesan dan berada sesuai dengan karateristik rasa musikal gamalan Banjar itu sendiri dengan laras salindru Banjar.

Adanya komponen pembangun yang melatari pemesanan gamalan Banjar oleh seorang pemesan kepada pelarasa gamalan Banjar juga menjadi bagian menarik dalam pembentukan larasan. Teori tentang kapital (modal) Piere Bourdieu. Dimana menurutnya Kapital(modal)terbentukpadakonsep masyarakat (society) yang didasari atas kelas (social life: class based) Wacquant, 1989: 1-3). Subjek atau individu menempati suatu posisi dalam ruang sosial multidemensional. Ruang tidak didefinisikan oleh keanggotaan kelas sosial, namun melalui jumlah setiap jenis modal yang dia miliki. Modal ini mencakup Jaringan sosial, nilai-nilaibudaya, danselera." (Bourdieu, 1989: 197). Teori tersebut digunakan sebagai penguat dari komponen-komponen yang melatarbelakangi pemesan dalam memesan gamalan- nya kepada para pelaras. Ada persamaan persepsi tentang modal yang dimaksud Bourdieu dan apa yang ditemukan pada diri pemesan di lapangan.

Kekuatan kapital dalam diri pemesan membaut gamalan Banjar yang ingin dipesan atau dibuatnya menjadi barang elit di masyarakat Banjar. Elitnya gamalan sekarang ini karena keberadaanya dalam sebuah lingkup sosial, tidak semua orang mampu memiliki gamalan. Hanya pemesan yang mempunyai komponen yang mampu memiliki gamalan Banjar, baik secara individu maupun secara komunal. Dari sisi pelarasgamalan Banjar kemampuan dalam menentukan jangkah-jangkah dan ukuranantar bilah nada, merupakan komponen utama yang harus dimilikinya. pembentukan jangkah-jangkah ini berasal dari pengetahuan emperik terhadap karakteristik rasa musikal budayanya (gamalan Banjar).

Peneliti menggunakan metode penelitian kualitatif sebagai metode utama dalam upaya mengumpulkan informasi dan data lapangan yang di dapatkan pada saat pengumpulan data.Metode ini digunakan untuk menghitung dan memvalidasi data kuantitatif yang didapatkan di lapangan pada saat pengukuran frekuensi nada-nada $g a-$ malan Banjar sehingga peneliti bisa mendapatkan gambaran jelas. Kreteria pengukuran laras dengan metode pengukuran pelarasan Sri Hastanto ${ }^{2}$ akan digunakan dalam menganalisa hasil pengukuran gamalan Banjar.

Mengungkap hubungan antara pemesan dan pelarasgamalanBanjar menjadi sebuah hal yang sangat menarik. Aspek sosial yang melingkupi dan selera pemesan atas gamalan yang ingin dimiliki menjadi sesuatu yang sangat menarik untuk diungkapkan. Tujuan pengungkapan ini akan menjadi salah satu bagian penting dalam proses pelarasan gamalanBanjar. Peranan suara dalang yang menjadi dasar pelarasan mampu menjadi daya tarik para pemesan. Bagaimana dalang membuat gamalan yang dibantu para pelarasgamalan agar sesuai dengan suaranya menjadi fenomena tersendiri. Hal-hal ini menjadi bagian yang belum banyak diketahui oleh orang banyak tentang masyarakat Banjar dalam membuat gamalanBanjar.

Pendekatan secara emperis terhadap penelitian ini dilakukan sebagai bentuk upaya mendapatkan data lapangan dengan memposisikan data-data tersebut berasal dari pengalaman dan pengetahuan para narasumber dalam pelarasan gamalanBanjar. Pengetahuan emperis peneliti yang merupakan bagian dari masyarakat gamalan Banjar menjadi salah 
satu bagian penting yang menghubungkan peneliti dengan para narasumber dan objek yang diteliti.

Data-data yang didapat dari pengetahuan emperis para narasumber serta pengalaman peneliti yang merupakan bagian dari masyarakat tersebut diekplanasi untuk menjawab analisis terhadap hubungan sosial pada siklus pelarasan gamalan Banjar. Frekuensi hasil pengukuran bilahan nada sarun pada gamalan Banjar digunakan untuk melihat banyaknya penggunaan suara dalang siapa dalam proses pelarasan yang diminta oleh para pemesan gamalan Banjar dan melihat larasan apa saja yang ada di Kalimantan Selatan.

\section{B. Marasuk sebuah konsep melaras gamalan Banjar}

Proses pelarasan gamalan Banjar pada masyarakat Banjar sendiri disebut marasuk ${ }^{3}$. Marasuk adalah suatu upaya membentuk tinggi rendahnya tiap bilahan nada yang dimulai dari instrumen sarun halus ${ }^{4}$. Proses marasuk ini melibatkan beberapa orang terdiri dari pelaras, pandai $i^{5}$ dan pemesan (dalang atau bukan dalang). Proses penentuan larasan dilakukan dengan cara mencocokkan 6 dengan suara seorang dalang yang dijadikan dasar pelarasan. Sampel suara dalang tersebut diambil pada saat dalang manambang ${ }^{6}$ atau melakakun sinden. Pemesan dan pelaras juga sangat bergantung pada penentuan suara dalang, pemilihan suara dalang tersebut biasanya dipengaruhi oleh kedekatan suara.

Dilihat dari komponen komponen marasuk sendiri yang terdiri dari suara dalang (pemesan) dan jarak nada (tumbang), serta adanya pangrasa ${ }^{7}$. Hubungan antara pemesan dan pelaras ini terdapat pada komponen penentuan suara acuan larasan (dalang atau pemesan). Hubungan yang terbentuk ini menjadi menarik karena hasil dari larasan ini akhirnya mampu merefleksikan ukuran nada dan siapa pemilik gamalan Banjar tersebut.

Komponen-komponen pembangun dari konsep marasuk agar tercapai sistem nada yang $c a r u k^{8}$ yaitu suara pemesan(pitch), jarak antar bilah nada, ukuran nada sebagai penghubung atau pengikat komponen tersebut. Jika dibuat dalam bentuk diagram maka akan berbentuk seperti dibawah ini:

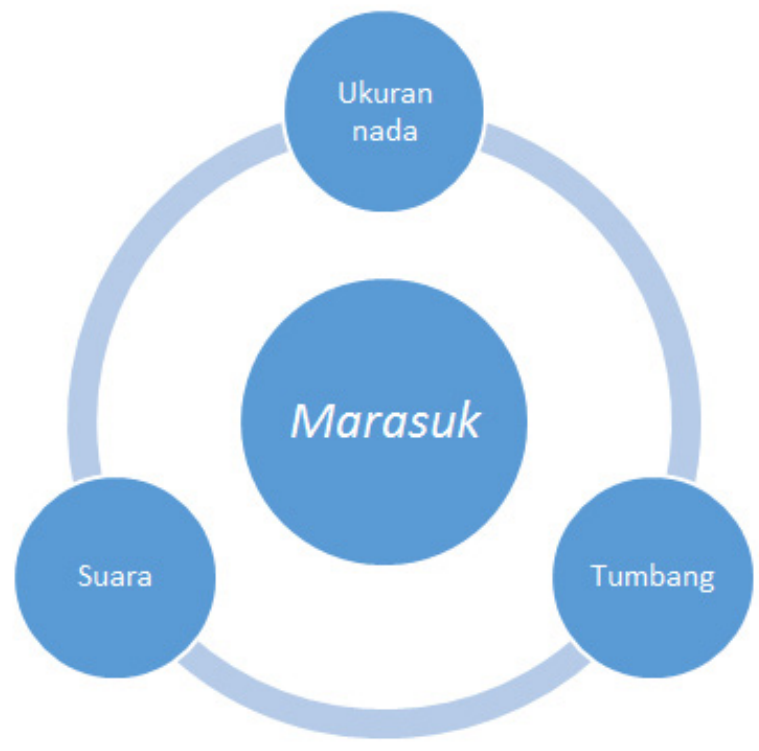

Skema 1. Diagram Konsep Marasuk yang dilakukan pelaras gamalan Banjar

Dari skema diatas dapat dilihat bahwa salah satu komponenmarasuk merupakan proses terjadinya hubungan antar pemesan dan pelaras gamalan Banjar. Hubungan tersebut membentuk sebuah kuasa yang dimiliki pemesan dalam penentuan awalan nada larasan. Setelah nada awal ditentukan antara pemesan dan pelaras gamalan Banjar, maka pembentukan jangkah dan ukurannada berada pada wilayah pelaras. Pemesan tidak memiliki kuasa lagi dalam penentuan jangkah dan ukurannada tersebut. Suara pemesan (dalang) dijadikan dasar pelarasan yang dilakukan oleh pelaras yang dibantu pandai. Hubungan yang mampu menciptakan sebuah larasan ini terbangun dari komponen-komponen yang dimiliki pemesan dan komponen yang dimiliki seorang pelaras.Dari hubungan antar pemesan dan pelaras ini akhinya menciptakan larasan yang berbeda-beda. Namun perbedaan ini hanya berada wilayah tinggi rendahnya larasan dan jangkahnya, tidak merubah pola tumbang-nya.

\section{Hubungan Pemesan dan Pelaras dalam proses marasuk}

Hubungan antara pemesan dan pelaras ini membangun kekuasan dalam diri pemesan. Kekuasaan yang hadir ini terlihat dari bagaimana seorang pemesan mendikte dan menetukan hasil akhir dari pembuatan gamalan banjar tersebut. Pemesan sendiri pada dasarnya memiliki modal dalam pemesanan gamalan Banjar. modal tersebut tidak hanya 
berupa finansial, namun lebih pada hal yang berada dalam sanubarinya.

Komponen-komponen pembangun dalam pemesanan gamalan Banjar yang dilakukan oleh pemesan kepada pelaras gamalan Banjar merupakan sebuah bentuk modal yang berada dalam ranah diri pemesan. Komponen-komponen tersebut terdiri dari modal budaya, selera, dan kedekatan timbre suara dengan seorang dalang atau modal suaranya sebagai sebuah dasar pelarasan.

Modal budaya menjadi faktor pertama yang membuat seseorang ingin membuat gamalan Banjar. Kesamaan budaya yaitu budaya Banjar tentu menjadikan pemesan berkeinginan memiliki gamalan Banjar sesuai kepantasan budaya itu sendiri. Ketentuan budaya ini menjadi dasar pemesanan yang kemudian dipengaruhi oleh selera dan kedekatan timbre suara pemesan dengan suara dalang yang dijadikan acuan larasan, kemudian direalisasikan dengan kemampuan kapital yang dimiliki oleh pemesan tersebut.

Modal budaya adalah sebuah identitas diri yang dimiliki oleh seseorang sebagai bagian dari masyarakat budaya tersebut. Dalam diri pemesan, modal budaya ini merujuk bahwa pemesan adalah bagian dari masyarakat budaya Banjar tersebut. Karena faktor ini menjadi dasar seseorang punya keinginan dalam memesan gamalan Banjar.

Perbedaan cara pemesanan antara pemesan yang merupakan dalang dan tidak berada pada penggunaan acuan larasannya. Jika pemesannya seorang dalang, maka pemesan tersebut akan menggunakan suaranya sendiri sebagai acuan pelarasan. Sedangkan pemesan yang bukan dalang akan melakukan pendekatan timbre suara antara suaranya dan suara seorang dalang yang pernah didengarnya yang kemudian dijadikan acuan larasan dan pembentukan jangkah-jangkah dilakukan oleh pelaras gamalan Banjar.Pengetahuan tentang kesamaan timbre ini di dapatkan dari pengalaman pemesan menonton pertunjukan wayang kulit baik secara langsung maunpun tidak langsung (rekaman). sehingga secara tidak langsung membentuk kepercayaan bahwa gamalan yang dimiliki oleh dalang tersebut bagus dan baik dan dijadikan dasar dalam pelarasan tersebut.Jika pemesan seorang dalang wayang kulit purwa Banjar maka pemesan tersebut memiliki kuasa atas gamalan yang dibuatnya karena suaranya sendiri yang digunakan sebagai acuan pelarasan. Suara dalang menjadi sumber utama yang ditransformasi dalam instrumen gamalan.
Selera yang ada dalam sanubari pemesan menjadi salah satu komponennya juga, dengan selera ini akhirnya pemesan mampu menentukan seperti apa gamalan yang diinginkannya (acuan larasaan dan bentuk). Selera ini muncul berdasarkan dari pengalaman dan pemaknaan pemesan terhadap gamalan Banjar itu sendiri. Sedangkan Pelaras gamalan Banjar hanya sebagai perantara teknis yang menjembatani antara pemesan dengan gamalan yang diinginkannya terutama dalam hal laras yang digunakan. Meskipun demikian, pelaras memiliki peranan yang sangat fundamental untuk menjadikan larasan bagus dan sesuai dengan apa yang diinginkan pemesannya. Kerja kreatif pelaras gamalan Banjar juga memerlukan bantuan seorang Pandai yang bertugas dalam membentuk bilahan-bilahan besi gamalan Banjar. Menurut Sunarno:

"pandai hanya mampu bekerja pada ranah fisik seperti malampar besi, mangulung besi, dan memotong sesuai ukuran yang diinginkan oleh para pelaras gamalan Banjar. Sedangkan dalam proses membentuk bunyi (nada) dan menyesuaikan dengan suara dalang harus dilakukan oleh seorang pelaras gamalan Banjar. Ini dikarenakan rasa musikal dan teknik mencari bunyi gamalan tidak dimiliki oleh pandai" (Wawancara, Sunarno: 23 September: 2016).

Pelaras gamalan Banjar memiliki rasa musikal yang hadir berdasarkan pengetahuan emperisnya sebagai panggamalanangamalan Banjar. Takaran ukuran nada dan tumbang nada yang dihadirkan dalam instrumen gamalan merupakan sesuatu yang sudah ada dalam sanubarinya.Komponen yang ada dalam diri pelaras dalam hubungannya dengan pemesan adalah penentuan tumbang dan ukurantinggi rendahnya setiap bilahan nada agar tidak payau ${ }^{10}$.

Dari skema dibawah ini kita bisa melihat komponen yang dimiliki oleh pemesan dan pelaras gamalan Banjar sehingga menghasilkan larasan $g a-$ malan Banjar yang caruk: 


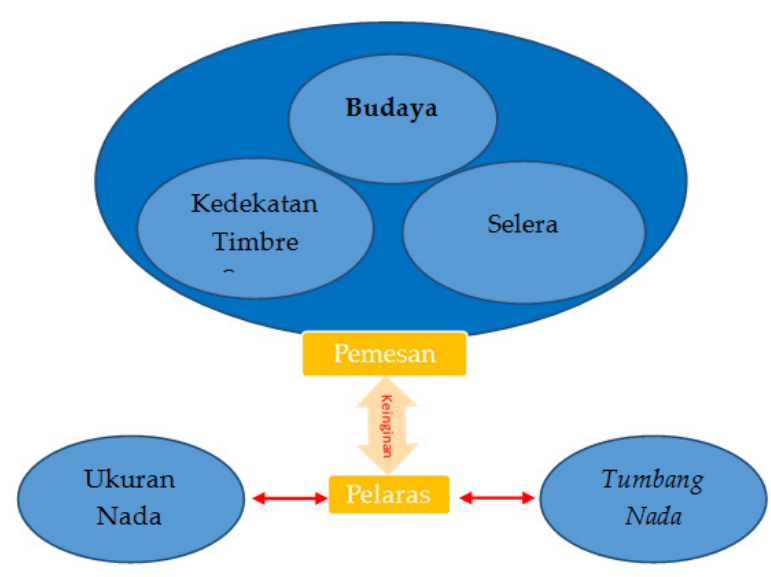

Skema 1. komponen pemesan dan pelaras dalam pelarasan gamalan Banjar

Berdasarkan pada teori tentang kapital (modal) yang diungkapkan Bourdieu dalam The Social Space And The Genesis Of Groups (1989) sejalan dengan apa yang terjadi dalam proses pemesanan gamalan Banjar, terungkap bahwa ada kekuatan kapital yang mendasari seseorang dalam pemesanan gamalan Banjar.kekuatan kapital ini menjadi sebuah konsep pemesanan yang terdiri dari beberapa komponen seperti budaya, kedekatan timbre suara, selera, dan finansial. Kekuatan kapital (modal) inilah yang bagi Bourdie mampu membentuk "a person", yaitu bagaimana seseorang mampu mengendalikan apa yang dia inginkan karena memiliki kekuatan kapital tersebut yang akhirnya membangun sebuah kelas sosial dalam lingkupnya. Kekuatan kapital ini mampu membangun jaringan sosial hingga membentuk kekuatan yang membedakan kelas-kelas sosial.

Bourdieu sendiri membagi kapital (modal) ini menjadi tiga bentuk yaitu, modal ekonomi (economic capital), Modal Sosial (sosial capital) dan modal budaya (culture capital). Ketiganya ini membentuk komoditasnya sendiri-sendiri namun saling berkaitan dalam pembentukan kelas-kelas sosial. Salah satu contoh pada modal budaya yang mampu membangun sebuah identitas atas apa yang dimilikinya. Selera yang terbentuk dari modal juga mampu memberi legitimasi atas apa yang dibentuknya dari modal (kapital) tersebut.

Dari masing-masing komponen yang ada dalam diri pemesan dan peleras, menciptakan sebuah hubungan yang membangun kuasa mereka masing-masing. Kuasa ini memberikan ruang pada masing-masing pemesan dan pelaras dan penentuan hasil larasan dalam prosesmarasuk.

Pada komponen suara pemesan, seorang pemesan adalah orang yang paling berkuasa dan memiliki kemampuan untuk mendikte pelaras agar membuatkan larasan yang dia inginkan. Marasuk nada awal yaitu nada 6 akan sangat memerlukan suaranya atau suara dalang agar laras yang diinginkan sesuai dengan apa yang dicita-citakan pemesan. Sedangkan dalam komponen tumbang nada dan ukuran nada menjadi kuasa pelaras. Kuasa ini hadir karena seorang pelaras gamalan harus mempunyai tataran sebagai berikut; seorang pelaras gamalan Banjar harus bergelut dalam dunia gamalan Banjar diatas 15 tahun, mempunyai kemampuan mengenali bunyi-bunyi gamalan Banjar, mampu bermain dengan benar dan baik. Kreteria tersebut sangat fundamental dalam menentukan kelayakan seseorang menjadi pelaras gamalan Banjar ${ }^{11}$.

Kemampuan dalam menentukan tumbangnada dan ukurannada adalah sesuatu yang sudah mengkristal dalam diri pelaras. Sebuah kemampuan yang lahir dari pengetahuan emperisnya dalam bersinggungan langsung dengan gamalan Banjar. oleh sebab itu seorang pelaras hanya memerlukan nada awalan 6 yang dilaras bersama pemesan sebagai acuan melaras. Nada-nada lainya kemudian akan dilaras berdasarkan tumbang nada dan ukuran nadayang sudah ada dalam sanubarinya.

Jika dilihat dari skema marasuk akan terlihat penghubung antara pemesan dan pelaras yang mana pada masing-masing komponen menjadi kuasa pemesan dan ada yang menjadi kuasa pelaras:

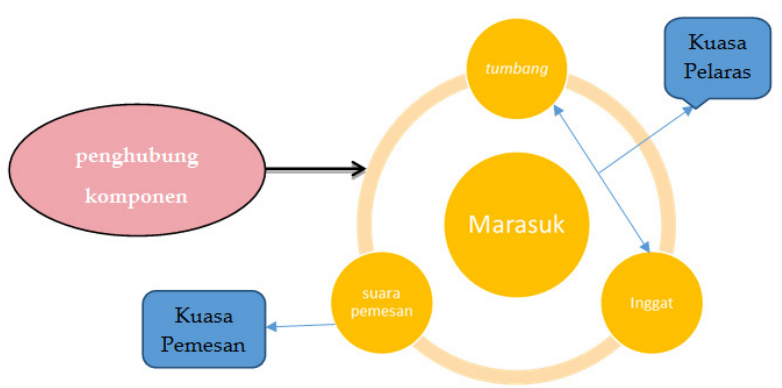

Skema 3. Hubungan pemesan dan pelaras dalam marasuk

Dalam proses marasuk gamalan Banjar seperti skema diatas dapat dilihat adanya pembagian kuasa atas komponen tersebut. Pembagian ini justru yang membuat terjadinya kontak antara pemesan dan pelaras. Kontak ini terjadi pada penentuan acuan laras yang akan digunakan. Kesamaan karakteristik rasa musikal antara pemesan dan pelaras menjadi komponen utama pada hubungan antara pemesan dan pelaras. 
Hubungan yang terbangun dari masing-masing komponen dalam diri pemesan dan pelaras yang menyatu dalam proses marasuk akan menghasilkan sebuah larasan yang caruk. Larasan yang caruk menandakan hubungan yan terjadi dalam marasuk gamalan berjalan dengan baik dan sesuai dengan kuasa masing-masing antar pemesan dan pelaras.

Perbedaan larasan ini sebenarnya hanya berada pada tinggi rendahnya bilahan nada gamalan Banjar dan tumbang nadanya. Ini dibuktikan dari hasil pengukuran ${ }^{12}$ beberapa gamalan Banjar di Sanggar Asam Marimbun (dalang Dimansyah, Sanggar Anak Padawa (dalang Taufik Rahman), dan Sanggar Taruna Jaya (dalang Rahmadi). Berikut hasil pengukuran tersebut:

\begin{tabular}{|c|c|c|c|c|c|c|c|}
\hline Nama nada & $\underline{6}$ & $\underline{9}$ & $B$ & $T$ & 5 & 6 & 9 \\
\hline Frekuensi & 518.4 & 613.8 & 692.5 & 791.4 & 908.9 & 1042 & 1239 \\
\hline Tumbang & 292 & 228 & 231 & 239 & 230 & 299 \\
\hline
\end{tabular}

Tabel 1.Ukuran Frekuensi nada dan tumbang nada sarun halus pada sanggar Asam Maribun (dalang Dimansyah)

\begin{tabular}{|c|c|c|c|c|c|c|c|}
\hline Nama nada & $\underline{6}$ & $\underline{9}$ & $B$ & $T$ & 5 & 6 & 9 \\
\hline Frekuensi & 532,8 & 629.6 & 707,5 & 812,4 & 952.1 & 1087 & 1286 \\
\hline Tumbang & 289 & & 01 & & 274 & 29 & 291 \\
\hline
\end{tabular}

Tabel 2. Ukuran frekuensi nada dan tumbang nada sarun halus pada sanggar Taruna Jaya (Laras dalang Rahmadi)

\begin{tabular}{|c|c|c|c|c|c|c|c|c|}
\hline Nama nada & $\underline{6}$ & $\underline{9}$ & $B$ & & & 5 & 6 & 9 \\
\hline Frekuensi & 533,8 & 627.9 & 706.3 & & & 940,7 & 1077 & 1282 \\
\hline Tumbang & 28 & & & 42 & & & & 301 \\
\hline
\end{tabular}

Tabel 3. Ukuran frekuensi nada dan tumbang nada sarun halus pada sanggar Anak Pandawa (Laras dalang Taufik Rahman)

Tiga sanggar yang menggunakan tiga larasan yang berbeda berdasarkan suara dalang masingmasing. Pengaruh pemilihan dalang dalam pelarasan gamalan Banjar tergambar dalam ukuran nada dantumbang nada. Ini menjadi sebuah bukti bahwa pemesan punya kuasa untuk memilih suara siapa yang menjadi dasar larasannya.

Perbedaan ini juga dilatarbelakangi oleh fungsi gamalan Banjar itu sendiri. Dalang menggunakan gamalan sebagai iringan pertunjukan wayang kulitnya sendiri sehingga gamalan tersebut harus sesuai dengan kemampuan jangkauan wilayah nada yang dimiliki dalang. Gamalan ini akhirnya sangat representatif dengan dalang sebagai pemilik gamalan atau sebagai bentuk selera dari pemesan dengan salah seorang dalang wayang kulit Banjar.

\section{KESIMPULAN}

Hubungan antara pemesan dan pelaras gamalan Banjar berada pada saat proses marasuk gamalan Banjar. Hubungan ini berada pada penentuan acuan nada larasan, menggunakan suaranya sendiri jika pemesan adalah seorang dalang atau menggunakan suara acuan dalang yang memiliki kedekatan timbre suara dengan pemesan tersebut jika pemesannya bukan seorang dalang.

Pemesan juga memiliki komponen pembangun dalam pembuatan gamalan Banjar, yaitu modal Budaya, selera, dan Kekuatan kapital dalam upaya merealisasikan keinginannya dalam membuat gamalan. semua komponen itu terbentuk dari pengalaman dan pemaknaan yang ada pada pemesan.

Larasan yang dipesan oleh seorang pemesan juga berpatokan pada fungsi gamalan itu sendiri. Bagi pemesan yang menggunakannya sebagai iringan wayang kulit maka akan menggunakan larasan sesuai dengan pemesan itu sendiri, sedangkan jika fungsinya hanya sebagai iringan saja, maka larasan akan ditentukan pemesan berdasarkan selera dan kedekatan timbre yang dimilikinya dengan dalang tertentu.

Pelaras gamalan Banjar sendiri, memiliki komponen utama yaitu kemampuan membentuk tumbang nada gamalan yang berdasarkan pada pengalaman emperisnya dalam bersinggungan dengan gamalan Banjar, baik sebagai panggamalanan ataupun dalang wayang kulit purwa Banjar. Kepekaan yang terbangun dalam membentuk jangkah ini merupakan sebuah intuisi musikal yang berada pada sanubari pelaras tersebut. Dalam proses marasuk ini, pelaras juga memerlukan bantuan pandai, untuk membentuk besi bilahan gamalan tersebut agar bunyinyang dihasilkan sesuai dengan keinginan pemesan.

Hubungan antar pemesan dan pelaras ini paling besar terjadi pada saat menentukan larasan yang akan digunakan. Seorang pelaras akan meminta pemesan yang seorang dalangmanambanguntuk melihat jangkauan suaranya. Sedangkan jika pemesan bukan dalang, maka pelaras hanya menanyakan larasan siapa yang digunakan.

Pemesan dan pelaras gamalan Banjar memiliki hubungan saling membutuhkan satu sama lain dengan bantuan dari dalang dan pandai dalam proses marasuk gamalan Banjar. Kedekatan timbre 
suara pemesan dengan timbre suara yang dimiliki seorang dalang menjadi penentuan pemesanan gamalan Banjar

Caruk dan payau menjadi capaian kualitas larasan yang berdasarkan pada hubungan antara pemesan dan pelarasa gamalan. Jika kualitas larasannya positif (bagus, pas, sesuai selera) maka dinamakan caruk. Namun jika kualitas larasannya tidak pas atau fals, maka larasan tersebut payau. Kualitas musikal pada larasan ini sangat tergantung juga pada pengalaman emperis pelaras gamalan, karena intuisi musikalnya yang berdasarkan pada karakteristik rasa musikal budayanya inilah yang membentuk jangkah-jangkah pada larasan salindru Banjar.

Terciptanya caruk dan payau tergantung pada hubungan pemesan dan pelaras dalam proses marasuk gamalan Banjar. gamalan yang mencapai caruk akan mampu menjadi representatif orang yang menjadi pemilik gamalan tersebut atau jika gamalan tersebut dilaras dengan acuan suara dalang, akan membuat pemesan mencapai selera yang diinginkannya.Pangrasa yang menjadi pengikat komponen marasuk adalah tali penghubung antar pemesan dan pelaras. Pemesan yang juga memiliki rasa musikal yang sama dengan pelaras terkoneksi dalam pembentukan larasan yang diinginkan.

\section{Catatan Akhir}

${ }^{1}$ Inggat atau ukuran memiliki arti batas. Dalam konteks komponen yang ada dalam marasuk, pemakaian kata inggat digunakan sebagai pengertian dari batas tolerasi antar bilahan nada.

${ }^{2}$ pertama, pemilihan gamalan Banjar harus merupakan gamalan yang memiliki kedudukannya tinggi dalam arti secara kesejarahan, pelarasnya, dan fungsinya diakui oleh masyarakat pemiliknya. Kedua, keadaaan gamalan Banjar tersebut dalam kondisi terbaik sehingga menghasilkan bunyi yang bagus. Ketiga, menggunakan alat tabuh yang tidak terlalu keras dan tidak terlalu lembut agar bisa menghasilkan bunyi yang panjang.keempat, proses pengukuran harus ditempat yang tenang tanpa ada gangguan suara-suara sekitarnya. (Di sampaikan Sri Hastanto dalam berbagai kesempatan di Perkuliahan Kajia Musik Nusantara 2, juga tertuang dalam buku Ngeng dan Reng: Persandingan sistem laras gamelan Ageng Jawa dan Gong kebyar Bali)

${ }^{3}$ (1) ma.ra.suk = memasang -- misalnya, "Inya lagi marasuk baju hanyar" = "Dia sedang memasang baju baru"; (2) ma.ra.suk.akan = mencocokkan -- misalnya, "Bubuhannya lagi marasukakan ukuran baju" = "Mereka lagi mencocokkan ukuran baju" (Kamus Bahasa Banjar Dialek Hulu-Indonesia, Edisi Pertama, Penerbit Departemen Pendidikan Nasional, Pusat Bahasa, Balai Bahasa Banjarmasin, 2008; hlmn. 208). Dalam konteks pelarasan marasuk menjadi suatu konsep melaras yang dilakukan oleh para pelaras.

${ }^{4}$ Sarun halus merupakan instrumen melodis yang ada dalam satu kelompok gamalan Banjar.

${ }^{5}$ Pandai adalah seseorang yang mempunyai keahlian dalam bidang pengolahan besi untuk dijadikan barang-barang tertentu seperti parang, pisau dan peralatan yang prosesnya di tempa.

${ }^{6}$ Manamabang yang berasal dari kata tambang merupakan sebuah bentuk lantunan pantun yang dilakukan dalang dalam sebuah pagelaran wayang kulit purwa Banjar

${ }^{7}$ Pangrasa adalah perasaan musikal yang dimiliki oleh seorang pelaras gamalan Banjar. dengan adanya pangrasa seorang pelaras dapat dengan mudah menentukan jangkah dan ukuran tinggi rendahnya bilahan nada dalam proses marasuk.

${ }^{8}$ Caruk adalah peristilahan yang digunakan untuk menyatakan keberhasilan seorang pelaras dalam membentuk larasan.

${ }^{9}$ Sunarno, Pelaras gamalan Banjar dan pangamalanan. sejak tahun 1980'an sudah menjadi pelaras gamalan Banjar.

${ }^{10}$ Payau adalah ungkapan yang ditujukan untuk mengungkapkan suatu kualitas larasan. Payau menandakan larasan dalam keadaan tidak sesuai dengan apa yang diharapkan.

${ }^{11}$ Pertanyaan peneliti Merupakan hasil wawancara dengan AW. Sarbaini pada tanggal 12 maret 2016, beliau menjelaskan bagaimana seseorang bisa menjadi pelaras Banjar. Jawaban tersebut didasari tentang bagaiaman seseorang bisa dengan mudah membuat gamalan? (wawancara tidak langsung)

${ }^{12}$ Data-data yang didapat dari pengukuran tersebut berupa frekuensi dengan angka-angka yang didapat melalui peralatan software pada Handphone Oppo neo 7 yaitu G-Strings tuneruntuk mendapatkan ukuran setiap bilahan nada dalam satuan $\mathrm{Hertz}(\mathrm{Hz})$ dan menggunakan media website www.Sengpilaudio.com untuk menghitung jarak antarbilahan nada dengan satuan Cent (C).Selain itu data-data tersebut juga direkam dengan Handphone Iphone $4 S$ lewat aplikasi AVR (NK NEWKLINE). 


\section{KEPUSTAKAAN}

Balai Bahasa Banjarmasin. Kamus Bahasa Banjar Dialek Hulu-Indonesia Edisi Pertama. Banjarbaru: Departemen Pendidikan Nasional, Pusat Bahasa, 2008

Bourdiue, Piere. Distictions: A Social Critique Of The Judgement Of Taste. Cambridge, Massachusetts: Harvard University Press, 1984

1989. The Social Space and The Genesis Of Groups. Translate by Richard Nice. Jurnal Theorie et Methodes. London, Beverly Hills, New Delhi: SAGE Sosicial Sciene Information.

Hastanto. Sri. 2009. Konsep Pathet Dalam Karawitan Jawa. Surakarta: ISI Press

Tim. Redefinisi Laras Slendro. Laporan Penelitian Tahun Pertama Tim Pascasarjana ISI Surakarta. Surakarta: ISI Surakarta, 2015

. Ngeng dan Reng: Persandingan Sistem Laras Gamelan Ageng Jawa dan Gong Kebyar Bali. Surakarta: ISI Press, 2012

Maizier, Pipit. (Habitus $x$ Modal $)+$ Ranah $=$ Praktik. Yogyakarta: Jalasutra, 2009

\section{Narasumber}

Sarbaini, AW. 66 Tahun, Datu Astaparana Kesultanan Banjar, Pelaras gamalan Banjar, Budayawan. Kalimantan Selatan, Barikin

Sunarno, 52 Tahun. Seniman Karawitan Banjar, Pelaras gamalan Banjar. Kalimantan Selatan, Barikin.

Taufik Rahman, 38 Tahun. Dalang, pelaras gamalan Banjar, seniman karawitan Banjar. Kalimantan Selatan, Panggung.

Dimansyah, 63 Tahun. Dalang wayang kulit purwa Banjar, Pelaras gamalan Banjar. Kalimantan Selatan, Pantai Hambawang

Rahmadi, 68 Tahun. Dalang wayang kulit purwa Banjar, Pelaras gamalan Banjar. Kalimantan Selatan, Talaga Langsat.

Busera Zuddin, 72 Tahun. Dalang wayang kulit purwa Banjar, Pelaras gamalan Banjar. Kalimantan Selatan. Tatah Barikin 